\title{
A large scale test of the gaming-enhancement hypothesis
}

\author{
Andrew K Przybylski ${ }^{\text {Corresp., }}{ }^{1}$, John C Wang ${ }^{2}$ \\ 1 Oxford Internet Institute, University of Oxford, Oxford, United Kingdom \\ 2 Nanyang Technological University, Singapore, Singapore \\ Corresponding Author: Andrew K Przybylski \\ Email address: andy.przybylski@oii.ox.ac.uk
}

A growing research literature suggests that regular electronic game play and game-based training programs may confer practically significant benefits to cognitive functioning. Most evidence supporting this idea, the gaming-enhancement hypothesis, has been collected in small-scale studies of university students and older adults. This research investigated the hypothesis in a general way with a large sample of 1,847 school-aged children. Our aim was to examine the relations between young people's gaming experiences and an objective test of reasoning performance. Using a Bayesian hypothesis testing approach, evidence for the gaming-enhancement and null hypotheses were compared. Results showed no substantive evidence supporting the idea that having preference for or regularly playing commercially available games was positively associated with reasoning ability. Evidence ranged from equivocal to very strong in support for the null hypothesis over what was predicted. The discussion focuses on the value of Bayesian hypothesis testing for investigating electronic gaming effects and the importance of open science practices and pre-registered designs to improve the quality of future work. 
1

2

3

4

5

6

7

8

9

10

11

12

13

14

15

16

17

18

19

20

21

22

23

24

25

26

27

28

29

30

31

32

33

34

35

36

37

38

39

40

41

42

43

44

45 1. Oxford Internet Institute, University of Oxford, United Kingdom

46 2. Nanyang Technological University, Singapore
A large scale test of the gaming-enhancement hypothesis

Andrew K. Przybylski ${ }^{1}$

Chee Keng John Wang ${ }^{2}$ 
47

48

49

50

51

52

53

54

55

\section{Abstract}

A growing research literature suggests that regular electronic game play and game-based training programs may confer practically significant benefits to cognitive functioning. Most evidence supporting this idea, the gaming-enhancement hypothesis, has been collected in small-scale studies of university students and older adults. This research investigated the hypothesis in a general way with a large sample of 1,847 school-aged children. Our aim was to examine the relations between young people's gaming experiences and an objective test of reasoning performance. Using a Bayesian hypothesis testing approach, evidence for the gamingenhancement and null hypotheses were compared. Results showed no substantive evidence supporting the idea that having preference for or regularly playing commercially available games was positively associated with reasoning ability. Evidence ranged from equivocal to very strong in support for the null hypothesis over what was predicted. The discussion focuses on the value of Bayesian hypothesis testing for investigating electronic gaming effects and the importance of open science practices and pre-registered designs to improve the quality of future work. 


\section{A large scale test of the gaming-enhancement hypothesis}

63

64

65

66

67

68

69

70

\section{Background}

Electronic games are now a ubiquitous form of entertainment and it is popularly believed that the time spent playing games might have positive benefits that extend outside of gaming contexts (Lenhart et al., 2008; McGonigal, 2012). This general idea, the gaming-enhancement hypothesis, posits that electronic gaming contexts influence a range of perceptual and cognitive abilities because they present complex, dynamic, and demanding challenges. A recent representative study of British adults and young people suggests this idea is widely held; Nine in ten think brain-training games provide an effective way to improve focus, memory, and concentration, and as many as two thirds have tried using these games to improve their own cognitive abilities (Wellcome Trust Ipsos MORI, 2014). This view is increasingly profitable and controversial (Nuechterlein et al., 2016). Given the intense public and private interest and investment in games as a way of improving cognition and reasoning, is noteworthy that the scientific literature investigating the gaming-enhancement hypothesis, though promising, is still at an early stage.

A growing body of research suggests that common varieties of electronic gaming experience might enhance general cognitive skills and abilities. These studies show that those who opt to, or are assigned to, play a range of commercially available games show measurable differences in terms of their visual and spatial abilities (Quaiser-Pohl, Geiser \& Lehmann, 2006; Green \& Bavelier, 2006), executive functioning, information processing (Maillot, Perrot \& Hartley, 2012), and performance at specialist skills such as laparoscopic surgery performance (Rosser et al., 2007). In particular, action games (Green \& Bavelier, 2006), strategy games (Basak et al., 2008), and multiplayer online games (Whitlock, McLaughlin \& Allaire, 2012), 
85 have been identified as having enhancing effects because they provide complex multi-tasking

86 environments that require players to integrate a range of sensory inputs. Researchers argue these

87 environments lead players to implement adaptive strategies to meet the varied demands of these

88 virtual contexts (Bavelier et al., 2012).

89 There is good reason to think that predispositions to engage specific kinds of games may

90 relate to cognitive performance and reasoning more broadly. For example, in studying skill

91 acquisition among strategy game players, researchers have reported evidence that differences in

92 brain volume are correlated with speed and performance in gaming contexts (Basak et al., 2011).

93 Exploration and learning in online gaming contexts closely mirror their offline analogues. Those

94 with pre-existing strengths tend to thrive at online gaming challenges initially, but those with low

95 levels of starting ability quickly close the performance gap (Stafford \& Dewar, 2013). It is

96 possible that such inclinations guide players to games that suit them. Findings from experimental

97 and quasi-experimental studies suggest both preference and experience matter in terms of small

98 to moderate effects across a wide range of cognitive performance indicators (Powers et al.,

99 2013).

100 Unfortunately, many of these studies have pronounced shortcomings that temper the

101 broad promise of the gaming-enhancement hypothesis (van Ravenzwaaij et al., 2014). For

102 example, most of the evidence supporting this view has been derived from small-scale surveys,

103 intervention studies in university settings, or from samples of older adults. A recent review of

104 this literature indicates a small yet consistent link between gaming and general reasoning ability

105 (Cohen's $d=0.24$ ), but the average sample size of studies examining the gaming-enhancement

106 hypothesis is only 32 participants (Powers et al., 2013). Perhaps as a consequence of such small

107 samples, the effects sizes reportedly linking games to cognitive abilities vary widely as a 
108 function of the methods used and the research groups investigating them. For example, studies

109 published in top-tier journals, while typically using very small samples, report substantially

110 larger effects compared to the rest of the literature (e.g., Cohen's $d=0.85$; Powers et al., 2013).

111 Moreover, despite the fact that games are played by the overwhelming majority of young people

112 (Lenhart et al., 2015), fewer than one in ten studies of the gaming enhancement study have

113 included participants under the age of 18. Childhood and adolescence see profound development

114 in cognitive abilities, and though negative effects of games are fiercely debated (Mills, 2014;

115 Bell, Bishop \& Przybylski, 2015), there is very little evidence concerning their possible positive

116 effects in this cohort. Further, nearly all studies examining gaming effects do so by studying

117 individual games or game types in isolation. So although there is reason to think that action

118 (Green \& Bavelier, 2006), strategy (Basak et al., 2011), and online game play (Whitlock,

119 McLaughlin \& Allaire, 2012) could have positive effects, it is not possible to know if attitudes,

120 preferences, or engagement with games in general, or specific subtypes in particular, are driving

121 the effects reported. Finally, there are a number of larger-scale intervention studies that show

122 evidence that does not support or directly contradicts the gaming-enhancement hypothesis

123 (Chisholm et al., 2010; Kennedy et al., 2011). Given the nature of the existing evidence, research

124 that systematically addresses these gaps in our knowledge is needed.

125 Present Research

126 The aim of the present research was to evaluate the extent to which everyday electronic

127 game engagement by young people relates to their general reasoning abilities. In particular, we

128 were interested to test how personal preferences for specific types of games related to reasoning

129 ability. In line with previous research, we hypothesized that those who gravitate towards action,

130 online, and strategy games would show higher levels of cognitive performance on a test of 
131 deductive reasoning ability (Basak et al., 2011). Our second goal was to test whether regular

132 active engagement with action, online, and strategy games was linked to cognitive ability. In line

133 with highly cited work in the area, we hypothesized that those playing these challenging games

134 for more than five hours each week (Green \& Bavelier, 2006) would show higher levels of 135 reasoning ability.

136

137

138

139

140

141

142

143

144

145

146

147

148

149

150

151

152

153

154

155

\section{Method}

\section{Data Source}

The present study utilized data collected in the first year of the Effects of Digital Gaming on Children and Teenagers in Singapore (EDGCTS) project. This dataset has been used in numerous previous publications focusing on the effects of gaming on motivation, dysregulated behavior, and interpersonal aggression in young people (Wan \& Chiou, 2006; Gentile et al., 2009; Wang, Liu \& Khoo, 2009; Chen et al., 2009; Choo et al., 2010; Gentile et al., 2011; Wang et al., 2011; Li, Liau \& Khoo, 2011; Chng et al., 2014; Prot et al., 2014; Gentile et al., 2014; Busching et al., 2015; Eichenbaum \& Kattner, 2015; Chng et al., 2015; Liau et al., 2015b; Choo et al., 2015; Liau et al., 2015a). A subsample of data from the EDGCTS project was used for the present study because it included self-reports of game play and an objective test of participants' reasoning abilities. Neither of these variables has been the focus of previously published studies, and a complete list of publications based on the EDGCTS dataset can be found on the Open Science Framework (osf.io/je786).

\section{Participants, Ethics, and Data}

Ethical clearance for data collection was granted through the Institutional Review Board of Nanyang Technological University in Singapore. Because of the combined length of the EDGCTS testing protocol, data collection was conducted over a four-day period to reduce 
156 participant burden and minimize sequence effects. The research was deemed low risk and

157 consent was obtained from parents through liaison teachers. Participants were informed that

158 involvement in the project was voluntary and that they could withdraw at any time. Ethical

159 review for this secondary data analysis was conducted by the research ethics committee at the

160 University of Oxford (SSH/OII/C1A-16-063).

161 In the first wave of the EDGCTS, quantitative data were collected from a total of 3,034

162 respondents. Gender information was present for 3,012 participants ( $99.3 \%$ of all cases), age data

163 were available for 2,813 participants (92.7\%), 2,135 participants provided the name of at least

164 one electronic game they played (70.4\%), and a total of 2,647 participants completed the

165 reasoning test (87.2\%). In sum, a total of 1,847 participants (60.9\% of all cases), provided valid

166 data and were included in subsequent analyses. These 1,847 participants ranged in age from 8 to

16716 years $(M=10.97, S D=1.99) ; 430$ of these identified as female and 1,417 identified as male.

168 The self-report materials, datasets, source code, and analysis code used in this study are available

169 from the Open Science Framework (osf.io/je786).

170 Outcome Variable

171 Reasoning Ability. Participants' deductive reasoning ability was assessed using the 60-

172 item Raven's Standard Progressive Matrices Plus (RPM) task (Raven, Raven \& Court, 1993).

173 The RPM, a widely used non-verbal test of reasoning ability, measures deductive intelligence by

174 prompting takers to identify the key missing visual element that completes patterns shown in a

175 series of increasingly complex $2 \times 2,2 \times 3,3 \times 3,4 \times 4$, and $6 \times 6$, matrices. This assessment was used

176 because it has been well validated across a range of demographic and cross-cultural cohorts

177 (Raven, 2000). Because our participants were school-aged children, they completed the version

178 of this multiple-choice test designed for group administration in educational settings for students 
179 between the ages of 8 and 16 years. Participants got a median of 29 of 60 matrices $(S D=4.44)$

180 correct, and age-adjusted reasoning scores were created for each participant in line with best-

181 practices (Savage-McGlynn, 2012). To this end, participants were segregated by age and their

182 raw performance scores were transformed into z-scores such that their performance was

183 standardized with respect to other children their age.

184 Explanatory Variables

185 Participants' electronic gaming was assessed through a series of questions asking about

186 the games they frequently played. Participants were requested to provide the names of up to three

187 games they played as well as an estimate of the amount of time they spend playing each. A total

188 of $446(24.1 \%)$ participants named a single game, 485 (26.3\%) participants named two games,

189 and $916(49.6 \%)$ named three games. The titles of named games were content coded to mark if

190 they belonged to one of the three game categories of interest: action games (e.g. Call of Duty,

191 Halo), multiplayer online games (e.g. Maple Story, World of Warcraft), or strategy games (e.g.

192 SimCity, StarCraft).

193 Game Preference. Preference scores were created for each participant using the game

194 names provided through self-report. If one or more of a participant's named games belonged to

195 the action, online, or strategy types, they were marked as expressing a preference for this kind of

196 game (coded 1); if not, they were counted as not having a preference for this game type (coded

197 0). This meant three preference scores, one for each game type, were computed for each

198 participant.

199 Regular Play. Data from game preference scores and participants'self-reported play

200 behavior were used to determine if participants were regular players of specific game types.

201 Scores were created for participants by combing information about the kinds of games they 
202 expressed preferences for and their self-reported amounts of weekly play. Amounts of weekly

203 play were computed summing participant estimates of weekday engagement, multiplied by five,

204 and estimates of weekend day engagement multiplied by two. Codes for game types were then

205 used to create one game engagement score for each type of game. In line with the approach

206 prescribed in previous research (Green \& Bavelier, 2006), participants were considered regular

207 active players of a game type if they invested five or more hours in a given game type in a week

208 (coded 1), and were coded 0 if they did not spend any time playing this game type in a typical

209 week. Table 1 presents summary statistics for participant game preferences and proportions of

210 active players of each game type.

Results

212

213

214 Because 36 correlations were conducted, we adjusted our $p$ value threshold for rejecting the null 215

\section{Preliminary Analyses}

Zero-order bivariate correlations between observed variables are presented in Table 2. hypothesis from 0.05 to 0.0014 (Holm, 1979). Analyses indicated that older participants were more likely to report higher levels of engagement with games as compared to younger ones $(r \mathrm{~s}=$ .130 to .278 ). Similarly, female participants were less likely to engage action and strategy games $(r \mathrm{~s}=-.128$ to -.217$)$. Gender was not significantly related to online game play nor was it related to age-adjusted reasoning ability (all $p \mathrm{~s}>0.0014)$. Because gender was not associated with our target outcome, which was centered on age, neither age nor gender were considered as covariates in hypothesis testing.

\section{Game Preference and Reasoning Ability}

In line with meta-analytic evidence a series of one-sided Bayesian independent samples ttests were used to quantify evidence for the game-enhancement hypothesis (Rouder et al., 2012; 
225 Powers et al., 2013; Morey, Romeijn \& Rouder, 2016), that specified preference for action,

226 online, and strategy games would be related to more deductive reasoning ability. Table 3

227 presents a summary of these results and observed means using a Cauchy prior of 0.24 , effect size

228 for quasi-experiments on measures of reasoning and intelligence, and a second prior effect size

229 for the enhancement hypothesis as reported in top-tier journals (Cohen's $d$ of 0.85; Powers et al.,

230 2013). Results provided very strong support for the null hypothesis over the alternative for action

231 games $\left(\mathrm{BF}_{10}=0.06 ; M_{0}=0.02, S D_{0}=1.00, M_{1}=-0.12, S D_{1}=0.97\right)$ and equivocal support for

232 alternative hypothesis for those who preferred strategy games $\left(\mathrm{BF}_{10}=1.45 ; M_{0}=-0.02, S D_{0}=\right.$

$\left.2331.02, M_{1}=0.08, S D_{1}=0.93\right)$, or online multiplayer games $\left(\mathrm{BF}_{10}=2.815 ; M_{0}=-0.05, S D_{0}=1.04\right.$,

$\left.234 M_{1}=0.05, S D_{1}=0.95\right)$. In examining the robustness of these Bayes factors it is clear that

235 evidence for effects larger than the average in the literature are also not supported. Results

236 derived using the larger effect sizes reported in top-tier journals for the enhancement effect, $d=$

2370.85 , appeared less likely as evidence was 1.25 and 57.01 times more likely to have been

238 observed under the null hypothesis than under the gaming-enhancement hypothesis (see Table

239 3). Figure 1, panels A, B, and C, present relative evidence for the gaming-enhancement

240 hypothesis for effect sizes ranging from a 0.0 to 1.5 . Taken together with the focused hypothesis

241 tests, these results indicated participants' preferences for these specific types of games were not

242 reliably linked to their deductive reasoning ability in these data.

243 Regular Game Play and Reasoning Ability

244 To examine the relations between regular action, strategy, or online game play and

245 reasoning ability, three additional Bayesian hypothesis tests were conducted following the

246 procedure used for game preferences. These models evaluated the relative evidence for the null

247 hypothesis as well as the gaming-enhancement hypothesis that postulates that playing these 
248 games for more than five hours each week would be associated with players' reasoning abilities.

249 Results provided moderate support for the null over the alternative hypothesis for action games

$250 \quad\left(\mathrm{BF}_{10}=0.12 ; M_{0}=0.02, S D_{0}=1.00, M_{1}=-0.07, S D_{1}=0.99\right)$, equivocal evidence for strategy

251 games $\left(\mathrm{BF}_{10}=1.120 ; M_{0}=-0.023, S D_{0}=1.02, M_{1}=0.08, S D_{1}=0.90\right)$, and equivocal to

252 moderate evidence for the null over the alternative hypothesis for multiplayer online games

$253\left(\mathrm{BF}_{10}=0.34 ; M_{0}=-0.04, S D_{0}=1.04, M_{1}=0.01, S D_{1}=0.97\right)$. Robustness checks using effect

254 size for the gaming enhancement hypothesis as reported in top-tier journals $(d=0.85$; Powers et

255 al., 2013) indicated evidence against the this hypothesis. Data were between 2.45 and 29.15

256 times more likely to be observed under the null hypothesis. Figure 1, panels D, E, and F, present

257 relative evidence for the gaming enhancement hypothesis for effect sizes ranging from of 0.0 to

258 1.5. Taken together with the previous results, these findings suggest it is unlikely that regular

259 active play of these games is systematically related to higher levels of general reasoning abilities.

\section{Discussion}

261

262

Overview

The promise that electronic games might positively influence human cognition is one that generates intense public, corporate, and scientific interest. The present research drew on a large sample of school-aged children and considered both their electronic gaming and cognitive performance to test of the gaming-enhancement hypothesis. Of central interest was the nature of the potential relations between children's self-reported preferences and gaming habits, and performance on a widely used test of deductive reasoning ability. Contrary to our expectations, the results did not provide substantial evidence in support of the hypothesis that the complex and

270 interactive experiences provided by commercially available games generalize to functioning 
271 outside of gaming contexts. In most cases, the evidence was in favor of the null hypothesis over

272 this account.

273 We hypothesized that those who express preferences for action, strategy, and multiplayer

274 online games, modes of play would show modestly higher levels of cognitive performance as

275 seen in previous smaller-scale studies (Basak et al., 2011). In contrast to what was expected, we

276 found equivocal to very strong evidence favoring the null hypothesis over this prediction.

277 Second, we hypothesized that regular engagement with games - playing five or more hours a

278 week of action, strategy, and multiplayer online games - would be linked with better reasoning

279 ability. Results from our analyses did not support this prediction. Evidence for regular strategy

280 game players were equivocal, but ranged from moderately to strongly in favor of the null for

281 these types of games. Taken together, our findings disconfirmed the gaming-enhancement

282 hypothesis, especially in terms of the larger effects reported in top-tier journals.

283 Our approach carries a number of strengths that should inform future studies of gaming

284 effects. First, evidence from this study relied on data provided by more than 1,800 young people,

285 a sample over 50 times larger than the average for studies examining gaming and cognition

286 (Powers et al., 2013). If research is to sort out the cognitive dynamics of play, larger and more

287 robust sampling is needed. Second, the Bayesian hypothesis testing approach we adopted used

288 open source software (JASP; Love et al., 2016), and allowed our study to quantify evidence for

289 the both the null hypothesis as well as a plausible alternative based on the existing literature.

290 Although the analysis plan for this study was not registered before the data were known, the

291 framework provides valuable empirical data that researchers can use as the basis, or prior, to

292 inform their own pre-registered designs. Finally, if indeed scholars are increasingly skeptical of

293 corporate attempts to sell games based on their purported upsides (e.g. Allaire et al., 2014), this 
294 vigor should be extended to all scientific inquiry in this area, for example by making the

295 materials, data, source and analysis code openly available. Future research making both positive

296 and negative claims regarding the effects of gaming on young people should do likewise.

\section{Limitations and Future Directions}

298 The present study presents a number of limitations that suggest promising avenues for

299 future work. First, because the data under study were cross-sectional they capture an easy to

300 interpret pattern of results that represent a snapshot in time. The data structure did so at the

301 expense of being able to draw causal inferences, and a complementary approach would examine

302 long-term salutary effects on cognition, ideally as a function of experimental manipulations of

303 game exposure. Second, data regarding participants' game preferences and regular play were

304 collected through self-report. Research indicates that some participants, and young people in

305 particular, provide exaggerated data when it comes to taboo activities such as sexual habits and

306 drug use (Robinson-Cimpian, 2014). It is possible that the average levels of engagement reported

307 by our participants disguised interesting patterns of engagement which merit inquiry. For

308 example, infrequent periods of high engagement (e.g. binge-playing), might have its own special

309 relations with reasoning abilities. If so, an experience-sampling based approach would be needed

310 to assess both between- and within-person variability with respect to the relation between

311 gaming and reasoning ability. Finally, the present study only used a single assessment of general

312 cognitive abilities, the Ravens Progressive Matrices task (Raven, 2000). There are many other

313 facets to intelligence and executive control that might be more sensitive to influence by regular

314 electronic gaming. Measures of naïve reasoning (Masson, Bub \& Lalonde, 2011), short and long-

315 term memory (Melby-Lervåg \& Hulme, 2013), audio processing (Liu \& Holt, 2011) might be

316 more liable to be influenced by gaming. If the gaming-enhancement hypothesis is not broadly 
317 accurate, it may find empirical support under conditions where these alternative aspects of

318 intelligence and reasoning abilities are under study.

319 Closing Remarks

320 The promise that popular games can enhance cognitive skills is an alluring one. Our

321 findings suggest there is no relation between interest in, or regular play of, electronic games and

322 general reasoning ability. As such, we advise that future research examining the potential

323 influences of gaming contexts on players should pre-register their analysis plans or follow the

324 registered reports process (e.g., Chambers, 2013; Elson, Przybylski \& Krämer, 2015). Such steps

325 would go a long way to reduce researcher degrees of freedom which might, along with

326 publication bias, affect conclusions drawn about the effects of gaming and cognitive

327 enhancement (Feynman, 1974; Gelman \& Loken, 2013; Nissen et al., 2016). While the research

328 presented here might be further informed by additional work conducted to these standards, our

329 findings above offer an early exploration of the gaming-enhancement hypothesis which is well-

330 powered and guided by open-science. 
332 Allaire JC., Bäckman L., Balota DA., Bavelier D., Bjork RA., Bower GH. 2014. A Consensus on the Brain Training Industry from the Scientific Community. Max Planck Institute for Human Development and Stanford Center on Longevity. http://longevity3. stanford.

Basak C., Boot WR., Voss MW., Kramer AF. 2008. Can training in a real-time strategy video game attenuate cognitive decline in older adults? Psychology and Aging 23:765-777. DOI: $10.1037 / \mathrm{a} 0013494$.

Basak C., Voss MW., Erickson KI., Boot WR., Kramer AF. 2011. Regional differences in brain volume predict the acquisition of skill in a complex real-time strategy videogame. Brain and Cognition 76:407-414. DOI: 10.1016/j.bandc.2011.03.017. edu/blog/2014/10/15/the-consensuson-the-brain-training-industryfrom-the-scientificcommunity/. Retrieved January 15:2015.

Bavelier D., Green CS., Pouget A., Schrater P. 2012. Brain plasticity through the life span: learning to learn and action video games. Annual Review of Neuroscience 35:391-416. DOI: 10.1146/annurev-neuro-060909-152832.

Bell V., Bishop DVM., Przybylski AK. 2015. The debate over digital technology and young people. BMJ 351:h3064. DOI: 10.1136/bmj.h3064.

Busching R., Gentile DA., Krahé B., Möller I., Khoo A., Walsh DA., Anderson CA. 2015. Testing the reliability and validity of different measures of violent video game use in the United States, Singapore, and Germany. Psychology of Popular Media Culture 4:97-111. DOI: $10.1037 / \mathrm{ppm} 0000004$.

Chambers CD. 2013. Registered Reports: A new publishing initiative at Cortex. Cortex 49:609610. DOI: 10.1016/j.cortex.2012.12.016. 
354 Chen VH-H., Lin W., Ng CW., Chai SL., Khoo ACE., Duh HB-L. 2009. Children's Choice of

355

356

357

358

359

360

361

362

363

364

365

366

367

368

369

370

371

372

373

374

375

Games: The Influence of Prosocial Tendency and Education-Level. In: Natkin S, Dupire J eds. Entertainment Computing - ICEC 2009. Lecture Notes in Computer Science. Springer Berlin Heidelberg, 110-119. DOI: 10.1007/978-3-642-04052-8_10.

Chisholm JD., Hickey C., Theeuwes J., Kingstone A. 2010. Reduced attentional capture in action video game players. Attention, Perception \& Psychophysics 72:667-671. DOI: 10.3758/APP.72.3.667.

Chng GS., Li D., Liau AK., Khoo A. 2015. Moderating Effects of the Family Environment for Parental Mediation and Pathological Internet Use in Youths. Cyberpsychology, Behavior, and Social Networking 18:30-36. DOI: 10.1089/cyber.2014.0368.

Chng GS., Liau A., Khoo A., Li D. 2014. Parental mediation and cyberbullying - a longitudinal study. Studies in Health Technology and Informatics 199:98-102.

Choo H., Gentile DA., Sim T., Li D., Khoo A., Liau AK. 2010. Pathological video-gaming among Singaporean youth. Annals of the Academy of Medicine, Singapore 39:822-829.

Choo H., Sim T., Liau AKF., Gentile DA., Khoo A. 2015. Parental Influences on Pathological Symptoms of Video-Gaming Among Children and Adolescents: A Prospective Study. Journal of Child and Family Studies 24:1429-1441. DOI: 10.1007/s10826-014-9949-9.

Eichenbaum A., Kattner F. 2015. The Role of Game Genres and the Development of Internet Gaming Disorder in School- Aged Children. Journal of Addictive Behaviors, Therapy \& Rehabilitation 4. DOI: 10.4172/2324-9005.1000141.

Elson M., Przybylski AK., Krämer N. 2015. “Technology and Human Behavior.” Journal of Media Psychology 27:203-204. DOI: 10.1027/1864-1105/a000170. 
376 Gelman A., Loken E. 2013. The garden of forking paths: Why multiple comparisons can be a

377 problem, even when there is no "fishing expedition" or "p-hacking" and the research

378 hypothesis was posited ahead of time. Department of Statistics, Columbia University.

379 Gentile DA., Anderson CA., Yukawa S., Ihori N., Saleem M., Lim Kam Ming, Shibuya A., Liau

380 AK., Khoo A., Bushman BJ., Rowell Huesmann L., Sakamoto A. 2009. The Effects of

381 Prosocial Video Games on Prosocial Behaviors: International Evidence From

382 Correlational, Longitudinal, and Experimental Studies. Personality and Social

383 Psychology Bulletin 35:752-763. DOI: 10.1177/0146167209333045.

384 Gentile DA., Choo H., Liau A., Sim T., Li D., Fung D., Khoo A. 2011. Pathological Video Game

385 Use Among Youths: A Two-Year Longitudinal Study. PEDIATRICS 127:e319-e329.

386 DOI: $10.1542 /$ peds.2010-1353.

387 Gentile DA., Li D., Khoo A., Prot S., Anderson CA. 2014. Mediators and Moderators of Long388 term Effects of Violent Video Games on Aggressive Behavior: Practice, Thinking, and 389 Action. JAMA Pediatrics 168:450. DOI: 10.1001/jamapediatrics.2014.63.

390 Green CS., Bavelier D. 2006. Effect of Action Video Games on the Spatial Distribution of

391 Visuospatial Attention. Journal of experimental psychology. Human perception and performance 32:1465-1478. DOI: 10.1037/0096-1523.32.6.1465.

Holm S. 1979. A Simple Sequentially Rejective Multiple Test Procedure. Scandinavian Journal of Statistics 6:65-70.

Kennedy AM., Boyle EM., Traynor O., Walsh T., Hill ADK. 2011. Video gaming enhances psychomotor skills but not visuospatial and perceptual abilities in surgical trainees. Journal of Surgical Education 68:414-420. DOI: 10.1016/j.jsurg.2011.03.009.

398 Lenhart A., Kahne J., Middaugh E., Macgill A., Vitak J. 2008. Teens, Video Games and Civics. 
399 Lenhart A., Smith A., Anderson M., Duggan M., Perrin A. 2015. Teens, Technology and $400 \quad$ Friendships.

401 Li D., Liau A., Khoo A. 2011. Examining the Influence of Actual-Ideal Self-Discrepancies, 402 Depression, and Escapism, on Pathological Gaming Among Massively Multiplayer 403 Online Adolescent Gamers. Cyberpsychology, Behavior, and Social Networking 14:535-

405 Liau AK., Choo H., Li D., Gentile DA., Sim T., Khoo A. 2015a. Pathological video-gaming 406 407 among youth: A prospective study examining dynamic protective factors. Addiction Research \& Theory 23:301-308. DOI: 10.3109/16066359.2014.987759.

Liau AK., Neo EC., Gentile DA., Choo H., Sim T., Li D., Khoo A. 2015b. Impulsivity, Self409 Regulation, and Pathological Video Gaming Among Youth: Testing a Mediation Model. Asia-Pacific Journal of Public Health 27:NP2188-NP2196. DOI: $10.1177 / 1010539511429369$.

Liu R., Holt LL. 2011. Neural Changes Associated with Nonspeech Auditory Category Learning Parallel Those of Speech Category Acquisition. Journal of Cognitive Neuroscience 23:683-698. DOI: 10.1162/jocn.2009.21392.

Love J., Selker R., Marsman M., Jamil T., Dropmann D., Verhagen AJ., Ly A., Gronau QF.,

417 Maillot P., Perrot A., Hartley A. 2012. Effects of interactive physical-activity video-game 418 training on physical and cognitive function in older adults. Psychology and Aging 27:589-600. DOI: 10.1037/a0026268.

Masson MEJ., Bub DN., Lalonde CE. 2011. Video-game training and naïve reasoning about object motion. Applied Cognitive Psychology 25:166-173. DOI: 10.1002/acp.1658. 
422 McGonigal J. 2012. Reality is broken: why games make us better and how they can change the 423 world; [includes practical advice for gamers]. London: Vintage Books.

424 Melby-Lervåg M., Hulme C. 2013. Is working memory training effective? A meta-analytic 425 review. Developmental Psychology 49:270-291. DOI: 10.1037/a0028228.

426

428

431

432

434 435

Mills KL. 2014. Effects of Internet use on the adolescent brain: despite popular claims, experimental evidence remains scarce. Trends in Cognitive Sciences 18:385-387. DOI: 10.1016/j.tics.2014.04.011.

Morey RD., Romeijn J-W., Rouder JN. 2016. The philosophy of Bayes factors and the quantification of statistical evidence. Journal of Mathematical Psychology. DOI: 10.1016/j.jmp.2015.11.001.

Nissen SB., Magidson T., Gross K., Bergstrom CT. 2016. Publication bias and the canonization of false facts. arXiv:1609.00494 [physics, stat].

Nuechterlein J., Rusk M., Soberats A., Johnson M. 2016. Federal Trade Commission, Plaintiff, V. Lumos Labs, Inc.

Powers KL., Brooks PJ., Aldrich NJ., Palladino MA., Alfieri L. 2013. Effects of video-game play on information processing: a meta-analytic investigation. Psychonomic Bulletin \& Review 20:1055-1079. DOI: 10.3758/s13423-013-0418-z.

Prot S., Gentile DA., Anderson CA., Suzuki K., Swing E., Lim KM., Horiuchi Y., Jelic M., Krahe B., Liuqing W., Liau AK., Khoo A., Petrescu PD., Sakamoto A., Tajima S., Toma RA., Warburton W., Zhang X., Lam BCP. 2014. Long-Term Relations Among ProsocialMedia Use, Empathy, and Prosocial Behavior. Psychological Science 25:358-368. DOI: $10.1177 / 0956797613503854$. 
444 Quaiser-Pohl C., Geiser C., Lehmann W. 2006. The relationship between computer-game

445

446

447

448

449

450

451

452

453

454

455

456

457

458

459

460

461

462

463

464

465

466 preference, gender, and mental-rotation ability. Personality and Individual Differences 40:609-619. DOI: 10.1016/j.paid.2005.07.015.

Raven J. 2000. The Raven's Progressive Matrices: Change and Stability over Culture and Time. Cognitive Psychology 41:1-48. DOI: 10.1006/cogp.1999.0735.

Raven J., Raven JC., Court JH. 1993. Manual for Raven's Progressive Matrices and Vocabulary Scales: General Overview (1993 Ed.). Oxford Psychologists Press.

van Ravenzwaaij D., Boekel W., Forstmann BU., Ratcliff R., Wagenmakers E-J. 2014. Action video games do not improve the speed of information processing in simple perceptual tasks. Journal of Experimental Psychology. General 143:1794-1805. DOI: $10.1037 / \mathrm{a} 0036923$

Robinson-Cimpian JP. 2014. Inaccurate Estimation of Disparities Due to Mischievous Responders Several Suggestions to Assess Conclusions. Educational Researcher 43:171185. DOI: $10.3102 / 0013189 X 14534297$.

Rosser JC., Lynch PJ., Cuddihy L., Gentile DA., Klonsky J., Merrell R. 2007. The impact of video games on training surgeons in the 21st century. Archives of Surgery (Chicago, Ill.: 1960) 142:181-186; discusssion 186. DOI: 10.1001/archsurg.142.2.181.

Rouder JN., Morey RD., Speckman PL., Province JM. 2012. Default Bayes factors for ANOVA designs. Journal of Mathematical Psychology 56:356-374. DOI: 10.1016/j.jmp.2012.08.001.

Savage-McGlynn E. 2012. Sex differences in intelligence in younger and older participants of the Raven's Standard Progressive Matrices Plus. Personality and Individual Differences 53:137-141. DOI: 10.1016/j.paid.2011.06.013. 
467 Stafford T., Dewar M. 2013. Tracing the Trajectory of Skill Learning With a Very Large Sample 468 of Online Game Players. Psychological Science:956797613511466. DOI:

469 $10.1177 / 0956797613511466$.

470

471

472 473

474

475

476

477

478

479

480

481

482

483

484
Wan C-S., Chiou W-B. 2006. Psychological Motives and Online Games Addiction: ATest of Flow Theory and Humanistic Needs Theory for Taiwanese Adolescents. CyberPsychology \& Behavior 9:317-324. DOI: 10.1089/cpb.2006.9.317.

Wang CKJ., Liu WC., Chye S., Chatzisarantis NLD. 2011. Understanding motivation in internet gaming among Singaporean youth: The role of passion. Computers in Human Behavior 27:1179-1184. DOI: 10.1016/j.chb.2010.12.012.

Wang CKJ., Liu WC., Khoo A. 2009. The Psychometric Properties of Dispositional Flow Scale2 in Internet Gaming. Current Psychology 28:194-201. DOI: 10.1007/s12144-009-9058$\mathrm{X}$.

Wellcome Trust Ipsos MORI 2014. Wellcome Trust Monitor 2, 2012.

Whitlock LA., McLaughlin AC., Allaire JC. 2012. Individual differences in response to cognitive training: Using a multi-modal, attentionally demanding game-based intervention for older adults. Computers in Human Behavior 28:1091-1096. DOI: 10.1016/j.chb.2012.01.012. 
485 Table 1

486 Participant Game Preferences and Engagement

\begin{tabular}{lcccccc}
\hline & \multicolumn{3}{c}{ Game Preference } & \multicolumn{3}{c}{ Regular Play } \\
\cline { 2 - 7 } & Action & Strategy & Online & Action & Strategy & Online \\
\hline Males & $21.7 \%$ & $25.1 \%$ & $45.1 \%$ & $13.0 \%$ & $17.2 \%$ & $33.7 \%$ \\
Females & $2.3 \%$ & $11.4 \%$ & $52.8 \%$ & $1.9 \%$ & $7.4 \%$ & $41.8 \%$ \\
Total & $17.2 \%$ & $21.9 \%$ & $47.2 \%$ & $10.4 \%$ & $14.9 \%$ & $34.1 \%$ \\
\hline
\end{tabular}

487 
488 Table 2

489 Observed Zero-Order Correlations

490

\begin{tabular}{|c|c|c|c|c|c|c|c|c|}
\hline & 2. & 3. & 4. & 5. & 6. & 7. & 8. & 9. \\
\hline Pearson's r & -0.070 & $0.132 *$ & $0.175^{*}$ & $0.130 *$ & $0.125^{*}$ & $0.215^{*}$ & $0.198^{*}$ & -0.000 \\
\hline
\end{tabular}

1. Age

2. Female

Pearson's r -

$$
0.217^{-}-0.140 * 0.062
$$

$-0.167 * 0.126^{-}$

$0.040 \quad-0.029$

3. Action Game Preference Pearson's r

$-\quad 0.078 * 0.123 * 0.943 * 0.067-0.111 * \quad-0.053$

4. Strategy Game

Pearson's $r$

$-\quad-0.061$

$0.0520 .959 *-0.060$

0.041

Preference

5. Online Game Preference Pearson's r

$$
-0.093 *-0.046 \quad 0.946 * 0.051
$$

6. Regular Action Game Pearson's r

$-\quad 0.090 * \quad-0.055 \quad-0.028$ Play

7. Regular Strategy Game Pearson's r Play

8. Regular Online Game Pearson's r Play

9. Deductive Reasoning Pearson's r Ability

491

492 Note. *Denotes p value below Bonferroni-Holm adjusted value of 0.0014 . 
Table 3.

Evidence from Bayesian Hypothesis Testing

\begin{tabular}{|c|c|c|c|c|c|c|c|c|c|c|}
\hline & \multicolumn{3}{|c|}{$\begin{array}{l}\text { Participants who did } \\
\text { not express preference } \\
\text { or play game type }\end{array}$} & \multicolumn{3}{|c|}{$\begin{array}{l}\text { Participants who did } \\
\text { express preference or } \\
\text { play game type }\end{array}$} & \multicolumn{2}{|c|}{$\begin{array}{l}\text { Average } \\
\text { Enhancement } \\
\text { Effect }^{1}\end{array}$} & \multicolumn{2}{|c|}{$\begin{array}{l}\text { Enhancement } \\
\text { Effect in Top } \\
\text { Tier Journals } \\
\end{array}$} \\
\hline & Count & Mean & SD & Count & Mean & SD & $\mathrm{BF}_{01}$ & $\mathrm{BF}_{10}$ & $\mathrm{BF}_{01}$ & $\mathrm{BF}_{10}$ \\
\hline Action Game Preference & 1530 & 0.02 & 1.00 & 317 & -0.12 & 0.97 & 16.38 & 0.06 & 57.01 & 0.02 \\
\hline Strategy Game Preference & 1442 & -0.02 & 1.02 & 405 & 0.08 & 0.93 & 0.69 & 1.45 & 2.06 & 0.48 \\
\hline Online Game Preference & 975 & -0.05 & 1.04 & 872 & 0.05 & 0.95 & 0.36 & 2.82 & 1.07 & 0.94 \\
\hline Regular Action Game Play & 1551 & 0.02 & 1.00 & 192 & -0.07 & 0.99 & 8.61 & 0.12 & 29.15 & 0.03 \\
\hline Regular Strategy Game Play & 1462 & -0.02 & 1.02 & 276 & 0.08 & 0.90 & 0.84 & 1.20 & 2.45 & 0.41 \\
\hline Regular Online Game Play & 1019 & -0.04 & 1.02 & 630 & 0.01 & 0.97 & 2.97 & 0.03 & 9.84 & 0.10 \\
\hline
\end{tabular}

496

497

498

499

500

Note. $\mathrm{BF}_{01}$ denotes evidence favoring the Null hypothesis. $\mathrm{BF}_{10}$ denotes evidence favoring the alternative hypothesis. 1. Average effect size for quasi-experiments on measures of reasoning and intelligence $(d=0.24$; Powers et al., 2013). 2. Average effect size for quasi-experiments on measures of general cognitive abilities published in top-tier journals $(d=0.85$; Powers et al., 2013). 
501 Figure 1.

502 Bayes factors for the comparison of electronic gaming to reasoning

503 ability as a function of the scale parameter of the Cauchy prior for effect

504 sizes ranging from 0.0 to 1.5 under the alternative hypothesis.

A

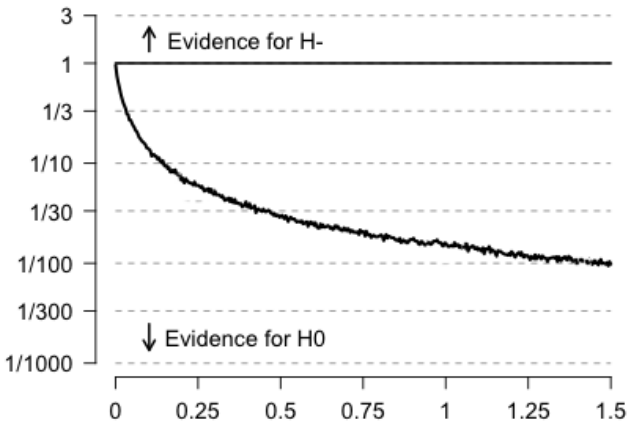

B

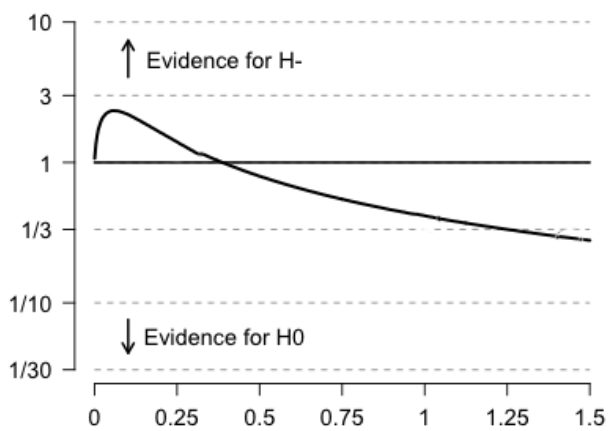

C

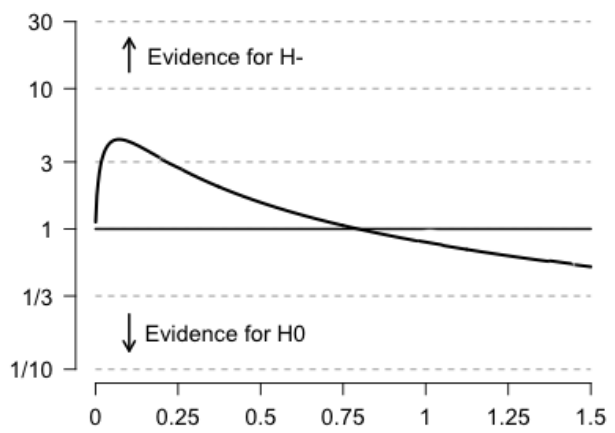

D

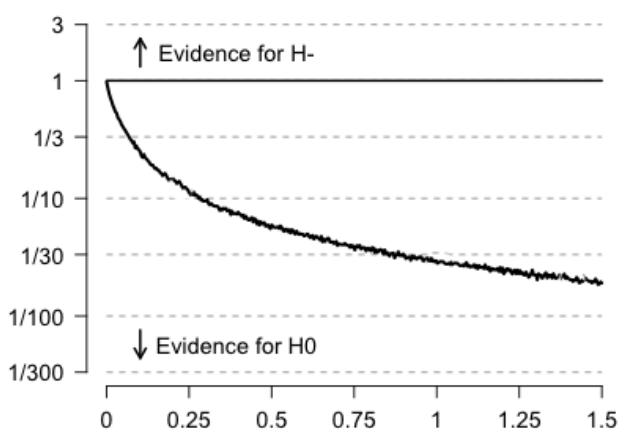

$\mathrm{E}$

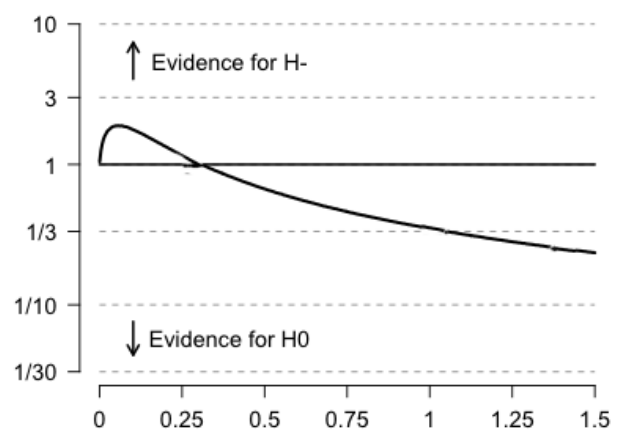

$\mathrm{F}$

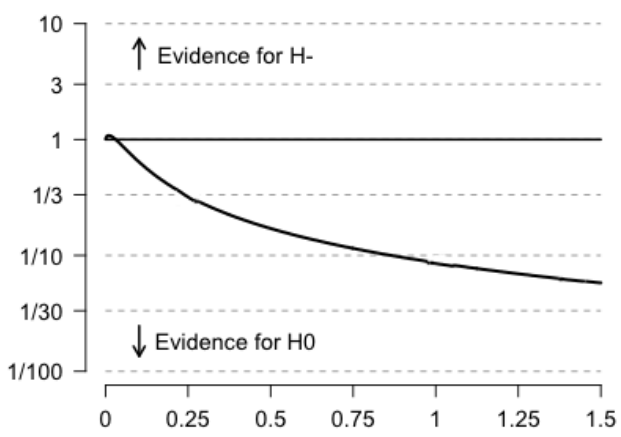

505

506

507

508

509

510

Note. Equal variances are assumed. Panels A through $\mathrm{C}$ represent game preference, and D through $\mathrm{F}$ represent regular game play. A. Action games. B. Strategy games. C. Online games. D. Action games. Strategy games. F. Online Games. 